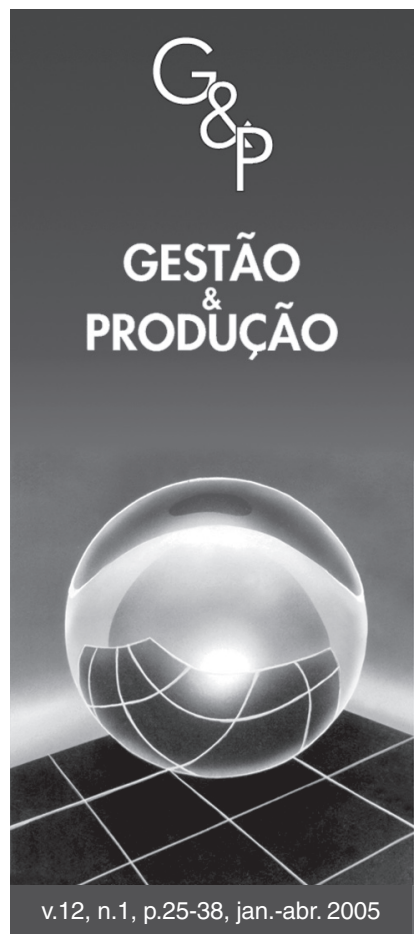

\title{
AVALIAÇÃO DO GRAU DE PRIORIDADE E DO FOCO DO PLANEJAMENTO E CONTROLE DA PRODUÇÃO (PCP): MODELOS E ESTUDOS DE CASOS
}

\author{
Flavio Cesar Faria Fernandes \\ Departamento de Engenharia de Produção, \\ Universidade Federal São Carlos, \\ Via Washington Luís, Km 235, CEP 13565-905, São Carlos, SP, \\ e-mail: dfcf@power.ufscar.br \\ Miguel Cezar Santoro \\ Departamento de Engenharia de Produção, \\ Escola Politécnica da Universidade de São Paulo, \\ Av. Prof. Almeida Prado, 128, travessa 2, CEP 05508-900, \\ Cidade Universitária, São Paulo, SP \\ e-mail: santoro@usp.br
}

Recebido em 27/10/2003

Aceito em 22/2/2005

Resumo

Neste artigo propomos um modelo que sugere qual o grau de prioridade que a empresa deve dar à sua função Planejamento e Controle da Produção (PCP) e outro que sugere qual o foco decisório que deve ter o PCP [foco em planejamento, foco em programação ou foco em ambos (planejamento e programação)]. Ambos os modelos são validados por meio de estudos de casos em 10 importantes empresas industriais brasileiras.

Palavras-chave: planejamento da produção, controle da produção, programação da produção, grau de prioridade, prática industrial.

\section{Introdução}

Num mundo globalizado, com acirrada competição, com inúmeras oportunidades de investimentos de recursos, as empresas devem investir recursos prioritariamente em funções ou processos de negócios mais críticos para o sucesso do negócio, ou seja, deve investir numa função de forma compatível com o seu grau de prioridade e com o nível de suas necessidades. Vamos analisar essa questão em relação à função Planejamento e Controle da Produção (PCP). Assim a principal questão de pesquisa deste artigo é: "Qual é o grau de prioridade que uma determinada empresa industrial deve dar ao PCP?" Como questão secundária da pesquisa temos: "Qual é o foco do PCP (planejamento, programação ou ambos) que uma determinada empresa industrial deve escolher para uma boa alocação de recursos dentro da função?"

Tentamos encontrar respostas a essas questões na literatura. Vários artigos foram encontrados (seção 2) que analisam diversos aspectos do PCP em empresas. Nenhum deles, porém, tenta responder a essas duas questões de pesquisa.

Com o objetivo de respondê-las, primeiramente entre- vistamos profissionais de 10 importantes empresas industriais brasileiras de ramos diferentes e, em geral, líderes no seu ramo de atividades. A Tabela 1 fornece o nome, cargo das principais pessoas que responderam a um questionário contendo 6 perguntas fechadas e 10 perguntas abertas e alguns atributos dessas 10 empresas. O questionário encontra-se no Apêndice 1. Os questionários foram respondidos no biênio 2001-2002.

Na seção 3.1 definimos alguns conceitos e apresentamos um resumo dos principais dados coletados. Inspirados na teoria de PCP e principalmente nos depoimentos (parte transcrita no Apêndice 2) propomos um modelo (seção 3.2) que sugere qual o grau de prioridade que uma dada empresa deve dar à sua função PCP. A seguir validamos este modelo para as empresas deste estudo e verificamos se elas alocam um volume coerente de recursos humanos e computacionais ao PCP.

Na Tabela 2 estão classificadas essas empresas de acordo com Buffa e Miller (1979) para dar uma visão geral e inicial dos casos estudados.

Na seção 3.3 propomos um modelo que sugere qual 
o foco do PCP que a empresa deve adotar e validamos o modelo por meio dos 10 estudos de caso.

A seção 4 enfatiza as principais conclusões do trabalho.

Vale observar que esta é uma pesquisa do tipo qualitativa cujas características podem ser encontradas em, por exemplo, Bryman (1989) e Creswell (1994). Quanto ao procedimento utilizado, esta é uma pesquisa do tipo estudo de caso e também é uma pesquisa do tipo teórico-conceitual, já que propomos dois modelos; outros tipos de pesquisa em gestão da produção quanto ao procedimento utilizado são (Filippini, 1997): experimental, pesquisa de avaliação (survey) e pesquisa-ação.

\section{Contextualização e referencial teórico}

Existe uma grande quantidade de artigos que abordam a questão da lacuna entre a teoria e a prática no PCP. Porém, o número de artigos em que isso é feito com base em levantamentos (estudos de casos) em empresas é bem menor e são eles que são objeto desta seção. Começando a resenha pelos trabalhos deste tipo nos EUA, Sanders e Manrodt (1994) fazem um survey em 500 empresas norte-americanas a respeito da aplicação de métodos quantitativos de previsão de demanda e chegam a tirar conclusões a respeito do por que, embora o conhecimento de tais técnicas tenha aumentado, o nível de uso continua pequeno e não tem crescido. Guide (2000) e Guide e

\section{Tabela 1. Alguns atributos das empresas dos estudos de caso.}

\begin{tabular}{|c|c|c|}
\hline Empresa & Contato Principal & Alguns Atributos da Empresa \\
\hline Abril & $\begin{array}{l}\text { Diretor de Planejamen- } \\
\text { to e Programação }\end{array}$ & $\begin{array}{l}\text { Editora líder no segmento de revistas. Estrutura verticalizada. Maior complexo gráfico da } \\
\text { América Latina. Dois canais de distribuição: um para bancas e outro para assinaturas. }\end{array}$ \\
\hline Alcoa & $\begin{array}{l}\text { Engenheiro de Qualida- } \\
\text { de e Planejamento }\end{array}$ & $\begin{array}{l}\text { A Alcoa Poços de Caldas é uma fábrica da Unidade de Negócio (BU) de Primários, ou seja, } \\
\text { produz apenas a matéria-prima para BUs de transformados e clientes externos. Os principais } \\
\text { produtos são Aluminas ( } 275.000 \text { ton/ano) - calcinadas, hidratadas ou especiais e Alumínio } \\
\text { (92.000 ton/ano) - na forma de lingotes, tarugos, pó e na forma líquida. }\end{array}$ \\
\hline $\begin{array}{l}\text { Baldan } \\
\text { (atual/ Agri- } \\
\text { tillage) }\end{array}$ & Chefe de PCP & $\begin{array}{l}\text { Fábrica pioneira de implementos agrícolas no Brasil. Foi criada em } 1928 \text { na cidade de Matão. } \\
\text { Projeta e fabrica uma grande variedade de equipamentos com tecnologia atual para preparo } \\
\text { de solo e plantio. Exporta para } 57 \text { países dos } 5 \text { continentes. }\end{array}$ \\
\hline $\begin{array}{l}\text { Deca (atual/ } \\
\text { Duratex) }\end{array}$ & Diretor Industrial & $\begin{array}{l}\text { Fornece materiais de acabamento para a construção civil. A Deca é líder brasileira no mer- } \\
\text { cado de Metais Sanitários, além de ocupar posição de destaque no mercado de louças. Os } \\
\text { componentes produzidos em São Paulo são montados em Jundiaí. }\end{array}$ \\
\hline Embraer & $\begin{array}{l}\text { Diretor da Qualidade } \\
\text { Corporativa }\end{array}$ & $\begin{array}{l}\text { Quarto fabricante de aviões do mundo. Em faturamento fica atrás da Boeing, Airbus e Bom- } \\
\text { bardier. Está em franca expansão conquistando mercados em muitos países do mundo. }\end{array}$ \\
\hline Faber & Gerente de PCP & $\begin{array}{l}\text { Empresa alemã fundada em } 1761 \text { e há mais de } 70 \text { anos no Brasil onde possui a maior fábrica } \\
\text { de lápis do mundo. Os principais produtos: Lápis Cor, Lápis Grafite, Canetas Esferográficas, } \\
\text { Lapiseiras, Marcadores, Apontadores e Tintas. São mais de } 50 \text { famílias de produtos com um } \\
\text { número bastante grande de Skus (mais de } 1.500 \text { Itens Acabados) e uma estrutura bastante } \\
\text { verticalizada. }\end{array}$ \\
\hline Inepar & Gerente de PCP & $\begin{array}{l}\text { A Inepar é uma das mais importantes Empresas do Setor Industrial de Bens de Capital do } \\
\text { País, operando no mercado de Equipamentos Sob Encomenda, com preponderância em equi- } \\
\text { pamentos de grande porte e pesados. }\end{array}$ \\
\hline Itautec-Philco & Vice-Presidente & $\begin{array}{l}\text { A Itautec-Philco atua nas áreas de informática, eletrônica de consumo e componentes ele- } \\
\text { trônicos, encontrando-se entre as líderes de mercado nas três áreas e pertencendo ao restrito } \\
\text { grupo de empresas com faturamento superior a } \mathrm{R} \$ 1 \text { bilhão. Pertence ao maior grupo privado } \\
\text { do Brasil, foi uma das primeiras empresas a obter o certificado ISO } 9000 \text { e exporta parte } \\
\text { considerável de sua produção. }\end{array}$ \\
\hline Klin & $\begin{array}{l}\text { Gerente de PCP e Su- } \\
\text { primentos }\end{array}$ & $\begin{array}{l}\text { A empresa Klin Calçados Infantis foi fundada em 1983, com o objetivo de atender ao seg- } \\
\text { mento infantil dando ênfase na qualidade e reinvestindo no parque industrial para tornar-se a } \\
\text { maior. Hoje, dentre os } 4 \text { segmentos de produtos infantis, é líder em } 3 \text {. Está estrategicamente } \\
\text { planejando (analisando cenário, tática do concorrente e produto adequado) para liderar os } \\
4 \text { segmentos no período de } 2 \text { anos. }\end{array}$ \\
\hline Villares & $\begin{array}{l}\text { Gerente da Unidade de } \\
\text { Cilindros }\end{array}$ & $\begin{array}{l}\text { Aços Villares S A fabrica cilindros para laminação de aços há quase } 50 \text { anos. As instalações } \\
\text { consistem de Forjaria, Fundição e Usinagem. Os cilindros (que podem pesar até } 80 \text { t cada) são } \\
\text { peças maciças que incorporam alguns componentes simples (anéis, chavetas) fabricados por } \\
\text { terceiros. Cada cliente tem um desenho próprio e as ligas, apesar de padronizadas, podem variar } \\
\text { ligeiramente para cada caso. } 50 \% \text { da produção é dirigida para o mercado internacional. }\end{array}$ \\
\hline
\end{tabular}


Tabela 2. Classificação geral dos sistemas produtivos das empresas.

\begin{tabular}{|c|c|c|c|c|}
\hline \multirow[t]{2}{*}{ Empresa } & \multicolumn{2}{|c|}{$\begin{array}{c}\text { Produção } \\
\text { predominante }\end{array}$} & \multicolumn{2}{|c|}{$\begin{array}{c}\text { Produz } \\
\text { predominantemente }\end{array}$} \\
\hline & contínua & intermitente & $\begin{array}{c}\text { para } \\
\text { estoque }\end{array}$ & $\begin{array}{c}\text { por } \\
\text { encomenda }\end{array}$ \\
\hline Abril & & $\mathrm{X}$ & & X \\
\hline Alcoa & $\mathrm{X}$ & & $\mathrm{X}$ & \\
\hline $\begin{array}{l}\text { Baldan } \\
\text { (atual/ } \\
\text { Agri- } \\
\text { tillage) }\end{array}$ & & X & & $\mathrm{X}$ \\
\hline $\begin{array}{l}\text { Deca } \\
\text { (atual/ } \\
\text { Duratex) }\end{array}$ & & $\mathrm{X}$ & $\mathrm{X}$ & \\
\hline Embraer & & X & & X \\
\hline Faber & & X & X & \\
\hline Inepar & & X & & X \\
\hline $\begin{array}{l}\text { Itautec- } \\
\text { Philco }\end{array}$ & & X & X & \\
\hline Klin & & $X$ & & X \\
\hline Villares & & $X$ & & X \\
\hline
\end{tabular}

Jayaraman (2000) fazem um levantamento das atividades de planejamento e controle da produção em empresas de remanufatura nos EUA.

Na Europa, Harsall et al. (1994), suportados pela descrição de 4 mini-casos de pequenas indústrias do Reino Unido, estabelecem as práticas correntes, identificam fatores que influenciam o PCP, e em particular a programação da produção e concluem com a discussão de uma abordagem para diminuir a lacuna entre a teoria e a prática e para desenvolver software de scheduling apropriado para pequenas empresas. Matsuura et al. (1995) mostram as diferenças entre empresas Finlandesas e Japonesas na aplicação do MRP (Materials Requirements Planning), JIT (Just-in-Time) e OPT (Optimized Production Technology).

Morris e Kim (1988) analisam o uso de sistemas de PCP na Coréia em 21 empresas industriais: a maioria (67\%) utiliza o sistema MRP; a maioria produz sob encomenda, mas possui um número de produtos finais e um número de linhas de produtos menores do que empresas dos EUA. Além disso, empresas que produzem em grandes lotes (pelo menos 80 unidades) e para estoque, não usam o MRP. Andijani e Selim (1996) examinam o quanto têm sido implantadas nas indústrias da Arábia Saudita as seguintes técnicas de controle da produção e materiais: automação, CIM (manufatura integrada por computador), MRP, JIT e TQM (gestão da qualidade total). Russo (1997) analisa a aplicabilidade dos sistemas de PCP na indústria pesada de bens de capital sob encomenda de produtos não repetitivos, baseando-se sua análise em um estudo de caso de uma importante empresa brasileira desse segmento. Mesquita (2001) analisa por meio de 5 estudos de casos os modelos e as práticas de planejamento e programação da produção na indústria farmacêutica. Pacheco e Santoro (2001) analisam as deficiências dos processos decisórios na escolha e adoção de sistemas de programação da produção em 6 grandes empresas brasileiras.

Segundo Persson (1981a), as principais abordagens da moderna Gestão da Produção são: a abordagem sistêmica baseada na teoria dos sistemas, sendo que ela é usada como uma forma de pensar e um método para descrever problemas complexos; a abordagem da teoria da decisão, que é fortemente influenciada pela administração científica e, mais recentemente, pela Management Science e pela disponibilidade de métodos de Pesquisa Operacional para tratar problemas que possam ser definidos; e a abordagem contingencial, que é fortemente influenciada pela teoria geral da administração e assume que existem algumas contingências importantes que determinam a relevância de diferentes problemas e, portanto, determinam a estrutura de problemas relevantes numa dada situação. Esse último pressuposto nos motivou a propor os modelos das seções 3.2 e 3.3 .

Para Persson (1981b) as classificações de sistemas de produção podem ser: unidimensional, bidimensional e multidimensional. Na seção 1 utilizamos uma classificação bidimensional. Na seção 3.2, propomos um modelo que sugere qual o grau de prioridade que a empresa deve dar ao PCP em função de algumas variáveis. Como referencial teórico será utilizada a classificação multidimensional de MacCarthy e Fernandes (2000). Esses autores entendem que a escolha dos sistemas de PCP e a complexidade e detalhamento desses sistemas dependem de 12 variáveis do sistema de produção: nível de repetitividade, tamanho da empresa, tempo de resposta, nível de automação, estrutura de produto, nível de customização, número de produtos, tipos de layout, tipos de pulmões de estoque, tipos de fluxo, tipos de montagem e tipos de organização do trabalho. Esses autores chegaram a essa proposta a partir da experiência própria e da análise de contribuições de vários outros autores, por exemplo Buffa e Miller (1979) e Wild (1971, 1972, 1995).

\section{O grau de prioridade e foco do PCP}

\subsection{Algumas definições e principais da- dos coletados}

A Tabela 3 mostra, para cada uma das 10 empresas, o grau de prioridade atribuída ao PCP há 10 anos, hoje e a expectativa para o futuro; e ainda o foco do PCP (em planejamento, em programação ou em ambos). Entendese que se o horizonte considerado é acima de 6 meses (em geral 12 meses), ou seja, de médio ou longo prazo, as decisões envolvem previsões e ocorre mais agregação do que detalhamento, então o foco é no planejamento. No 
Tabela 3. O grau de prioridade e foco do PCP nas empresas.

\begin{tabular}{lllll}
\hline Empresa & $\begin{array}{c}\text { Grau de prioridade } \\
\text { atual do PCP }\end{array}$ & $\begin{array}{c}\text { Grau de prioridade } \\
\text { atual em relação há } \\
\mathbf{1 0} \text { anos }\end{array}$ & $\begin{array}{c}\text { Perspectiva do grau de } \\
\text { prioridade no futuro } \\
\text { em relação a hoje }\end{array}$ & $\begin{array}{c}\text { Foco do PCP na } \\
\text { empresa }\end{array}$ \\
\hline Abril & Muito grande & Maior & Maior ou igual & Ambos \\
Alcoa & Muito pequena & Menor & Menor ou igual & Planejamento \\
Baldan & Grande & Muito maior & Maior & Planejamento \\
Deca & Grande & Muito maior & Maior & Planejamento \\
Embraer & Grande & Maior & Maior & Ambos \\
Faber & Grande & Maior & Maior & Ambos \\
Inepar & Grande & Maior & Maior & Ambos \\
Itautec-Philco & Grande & Igual & Maior nos processos estra- & Ambos \\
& & & tégicos & Ambos \\
Klin & Muito grande & Maior & Maior ou igual & Programação \\
Villares & Muito grande & Maior & Maior ou igual & \\
\hline
\end{tabular}

controle da produção tomam-se decisões de curto prazo para execução de modo a regular o fluxo de materiais. Têm-se basicamente três possibilidades:

a) controlar a produção baseando-se na programação da produção;

b) controlar a produção a partir do nível de estoque e regras simples de seqüenciamento (por exemplo, prioridade para o item com maior número de cartões Kanban na faixa vermelha) operacionalizadas pelos trabalhadores do chão de fábrica; e

c) combinar as abordagens (a) e (b), por exemplo, programando diariamente o estágio final (por exemplo, a montagem) e controlando os estágios anteriores em função do nível de estoque e de regras simples de prioridade. Se a empresa adota a abordagem (b), consideramos que a empresa não foca a programação da produção, e se adota (a) ou (c) consideramos que a programação da produção é focada. Na programação da produção, o horizonte é de curto prazo (em geral menor que 3 meses), as decisões consideram detalhes do sistema produtivo e as previsões são menos importantes do que no caso de planejamento da produção.

Pela Tabela 3, na qual estão os principais dados coletados, observa-se que: se o foco é em ambos ou é em programação, o grau de prioridade que a empresa dispensa à função é grande ou muito grande; se o foco é em planejamento, não necessariamente é alto o grau de prioridade que a função recebe na empresa. Vale ressaltar que, se o sistema de produção é complexo, a programação é uma atividade complexa pelo grande número de detalhes que ela envolve. A complexidade das restrições tecnológicas ou organizacionais aumenta quanto maior for a variedade de produtos, maior o número de níveis da estrutura de produto, quanto mais complexo for o fluxo de materiais (F12 o mais complexo e F1 o mais simples, segundo a classificação de MacCarthy e Fernandes (2000)), entre outros fatores.

No Apêndice 2 apresentamos um resumo dos depoimentos relativos ao grau de prioridade do PCP em cada uma das dez empresas dos estudos de casos.

\subsection{Análises e modelo proposto para o grau de prioridade que se deve atribuir ao PCP}

Propomos um modelo que sugere qual o grau de prioridade que a empresa deve dar ao PCP em função de algumas variáveis. Como já foi dito, MacCarthy e Fernandes (2000) entendem que a escolha dos sistemas de PCP e a complexidade e detalhamento desses sistemas dependem de 12 variáveis do sistema de produção. Vamos considerar essas variáveis de uma forma mais simplificada visando obter um modelo simples. Da variável repetitividade, que é função da variedade e volume de produção, vamos isolar a variável variedade de produtos finais. A variável Tempo de Resposta é função, dentre outras coisas, se a produção é sob encomenda ou para estoque. Vamos considerar ainda a variável complexidade da estrutura de produto de uma forma binária (complexa ou simples). Uma variável não considerada em MacCarthy e Fernandes (2000) é a competitividade do mercado (muito competitivo ou pouco competitivo). As demais variáveis vamos sintetizá-las em uma única variável: complexidade das restrições tecnológicas ou organizacionais (muito complexas ou pouco complexas). Assim, para uma dada empresa:

$\mathrm{M}=1$ se há muita competição no mercado e 0 caso haja pouca competição;

$\mathrm{P}=1$ se a empresa produz sob encomenda ou 0 se produz para estoque;

$\mathrm{E}=1$ se a estrutura dos produtos é complexa ou 0 se é simples; 
$\mathrm{R}=1$ se as restrições tecnológicas ou organizacionais são complexas ou 0 se simples; e

$\mathrm{V}=1$ se é alta a variedade de produtos finais ou $0 \mathrm{em}$ caso contrário.

$$
\mathrm{S}=\mathrm{M}+\mathrm{P}+\mathrm{E}+\mathrm{R}+\mathrm{V}
$$

$\mathrm{S}$ nos fornece a sugestão do modelo para o grau de prioridade que a empresa deve dar à função de PCP. Assim: se $S=5$ o grau de prioridade dado pela empresa à função deve ser muito grande; se $\mathrm{S}=4 \rightarrow$ prioridade grande; $\mathrm{S}=3 \rightarrow$ considerável; $\mathrm{S}=2 \rightarrow$ pequena; $\mathrm{S}=1 \rightarrow$ muito pequena.

As 5 variáveis independentes do modelo $(\mathrm{M}, \mathrm{P}, \mathrm{E}, \mathrm{R}$, $\mathrm{V})$ estão relacionadas direta ou indiretamente aos dois grandes objetivos de um sistema produtivo:

a) atender à demanda em termos de quantidade e prazo e, portanto, com tempo de resposta e nível de serviço adequados ao grau de competição do mercado (variáveis $\mathrm{M} \mathrm{e} \mathrm{P);} \mathrm{e}$

b) usar da melhor forma possível os recursos e, dependendo das variáveis $E, R$ e $V$, isso só pode ser conseguido com um sistema de PCP apurado.

As 10 empresas são líderes em pelo menos um segmento de atuação. Cabe ressaltar que o sucesso de uma empresa depende, entre outros fatores, dos executivos priorizarem de forma adequada os investimentos nas várias funções. A partir dos depoimentos (transcritos no Apêndice 2) e da posição na estrutura organizacional do PCP na empresa, avaliamos o grau de prioridade (AGP = Avaliação do Grau de Prioridade) para cada empresa. Na Tabela 4 estão o AGP e os valores das variáveis M, P, E, R, V e S. Comparando AGP e S, o modelo, apesar de simples, se mostra validado.

Analisando os depoimentos (Apêndice 2), o grau de prioridade do PCP, exceto na Alcoa, cresceu nos últimos 10 anos e este grau de prioridade deve ser mantido ou aumentado nos próximos anos. Na Alcoa o grau de prio-

Tabela 4. Validação do modelo para determinação do grau de prioridade que a empresa deve dar à função de PCP.

\begin{tabular}{lccccccc}
\hline Empresa & M & P & E & R & V & S & AGP \\
\hline Abril & 1 & 1 & 1 & 1 & 1 & 5 & 5 \\
Alcoa & 0 & 0 & 0 & 1 & 0 & 1 & 1 \\
Baldan & 1 & 1 & 1 & 0 & 1 & 4 & 4 \\
Deca & 1 & 0 & 0 & 1 & 1 & 3 & 4 \\
Embraer & 1 & 1 & 1 & 1 & 0 & 4 & 4 \\
Faber & 1 & 0 & 1 & 1 & 1 & 4 & 4 \\
Inepar & 1 & 1 & 1 & 1 & 0 & 4 & 4 \\
Itautec & 1 & 0 & 1 & 1 & 1 & 4 & 4 \\
Klin & 1 & 1 & 1 & 1 & 1 & 5 & 5 \\
Villares & 1 & 1 & 0 & 1 & 1 & 4 & 5 \\
\hline
\end{tabular}

ridade diminuiu (e deve continuar muito pequena) após a implantação do sistema de puxar a produção controlada pelo nível de estoque baseado no Sistema Toyota de Produção; o controle da produção passou a ser operacionalizado pelos trabalhadores do chão de fábrica segundo regras simples de seqüenciamento.

O quanto as empresas investem em pessoas e softwares para o PCP está correlacionado com o grau de prioridade que elas atribuem à função (veja Tabelas 5 e 6).

Quanto maior o grau de prioridade dado ao PCP (veja Tabela 7), mais as decisões são baseadas em softwares. Por exemplo, na Alcoa as decisões são baseadas apenas em regras de decisão simples aceitas internamente. Por outro lado, não há um padrão a seguir; cada empresa usa uma combinação diversificada priorizada de forma distinta. Por exemplo, na Abril, em primeiro lugar as decisões são baseadas em sistemas informatizados desenvolvidos internamente, em segundo lugar, exclusivamente na experiência do decisor e, em terceiro lugar, na experiência do decisor apoiada em conceitos teóricos.

Atribuindo uma pontuação de 10 pontos para o primeiro colocado segundo cada empresa (Tabela 7), 6 para o segundo, 4 para o $3^{\circ}$., 3 para o $4^{\circ}$., 2 para o $5^{\circ}$. e 1 para o $6^{\circ}$., temos a seguinte priorização geral dos processos de tomada de decisão no PCP:

$1^{\circ}$. lugar) baseado em sistemas informatizados desenvolvidos internamente (57 pontos);

$2^{\circ}$. lugar) baseado na experiência do decisor apoiada em conceitos teóricos (45 pontos);

$3^{\circ}$. lugar) baseado em regras de decisão simples aceitas internamente (40 pontos);

$4^{\circ}$. lugar) baseado em sistemas informatizados comerciais (36 pontos);

$5^{\circ}$. lugar) baseado exclusivamente na experiência do decisor (28 pontos); e

$6^{\circ}$. lugar) baseado em modelos matemáticos (9 pontos).

\subsection{Foco do PCP}

Com base nos conceitos definidos na seção 3.1, elaboramos um modelo (validação pela Tabela 8) que prevê qual deve ser o foco da empresa: planejamento, programação ou ambos:

- Se a empresa produz para estoque, o horizonte de planejamento deve ser de médio ou longo prazo, portanto, deve haver um foco em planejamento;

- Se a empresa produz sob encomenda, ela deve ter um foco em programação; e

- ((Se a empresa produz sob encomenda) ou (é alta a variedade de produtos finais)) e ((importa insumos) ou (exporta parte significativa da sua produção)) então ela deve ter um foco tanto em planejamento como em programação. 
A última coluna da Tabela 8 é a resposta a uma pergunta fechada feita ao contato principal (Tabela 1) que trabalha na empresa. Em $80 \%$ dos casos a sugestão do modelo coincide com o foco na empresa.

\section{Conclusões finais}

O volume alocado de recursos a uma função deve ser compatível com o seu grau de prioridade e com o nível de

Tabela 5. Prioridade do PCP e Capacitação das pessoas que trabalham no PCP.

\begin{tabular}{|c|c|c|}
\hline Empresa & AGP & Capacitação das pessoas que trabalham no PCP \\
\hline Abril & 5 & $\begin{array}{l}\text { Atualmente contamos com pessoas que conhecem conceitos básicos de programação. Muitas delas possuem } \\
\text { curso superior em Engenharia e Administração. Esta capacitação evoluiu. Muitos funcionários da função } \\
\text { têm mais de } 10 \text { anos de casa. No futuro, percebemos que as pessoas do PCP precisarão de capacitação } \\
\text { diferenciada. }\end{array}$ \\
\hline Alcoa & 1 & $\begin{array}{l}\text { Atualmente temos pessoas de nível técnico exercendo essa função. Em relação aos últimos } 10 \text { anos, essa } \\
\text { capacitação permaneceu estável. As pessoas que exercem essa função dentro da Alcoa são pessoas mais } \\
\text { antigas, muitas delas, ex-operadores que fizeram algum curso técnico. }\end{array}$ \\
\hline Baldan & 4 & $\begin{array}{l}\text { O quadro de funcionários lotados no PCP atualmente é maior, tanto em número como em capacitação pro- } \\
\text { fissional. Até o final de } 1996 \text { a seção contava com } 02 \text { funcionários, sendo um técnico em Contabilidade e } \\
\text { outro com } 1^{\circ} \text { grau completo. Atualmente o PCP possui o status de departamento, tendo em seus quadros } \\
15 \text { funcionários. }\end{array}$ \\
\hline Deca & 4 & $\begin{array}{l}\text { Focando apenas a função de Planejamento da Produção e Compras, têm-se um gerente e outro engenheiro } \\
\text { e } 4 \text { administradores de empresas. A equipe possui ampla visão de desempenho da companhia. Houve uma } \\
\text { evolução no perfil dos funcionários da função. No passado, o programador da produção era apenas um } \\
\text { ativador da produção, lutando para atingir os volumes pré-definidos. Atualmente contamos com equipe } \\
\text { comprometida com os resultados do negócio, com muito mais informação e com metas de desempenho } \\
\text { muito melhor definidas. A tendência é contar com equipe mais apta para compreender cada movimento, e } \\
\text { não apenas o de mover as peças. }\end{array}$ \\
\hline Embraer & 4 & $\begin{array}{l}\text { Os profissionais que atuam em planejamento possuem nível superior, a maioria dos que atuam em progra- } \\
\text { mação possui curso técnico e, no acompanhamento da produção, a escolaridade mínima exigida é o segundo } \\
\text { grau. São profissionais com experiência na função, adquirida na própria empresa ou vindos de outras. Tem } \\
\text { aumentado, com as exigências de escolaridade mínima para cada função dentro do PCP. Além disso, bus- } \\
\text { ca-se uma constante atualização dos conhecimentos por meio de cursos de extensão universitária, MBAs, } \\
\text { palestras e cursos internos e certificações de profissionais em associações como APICS. }\end{array}$ \\
\hline Faber & 4 & $\begin{array}{l}\text { De maneira geral, as pessoas que coordenam os vários PCPs da empresa têm graduação em Engenharia de } \\
\text { Produção ou Pós-Graduação na função com experiência em média de 6-8 anos. A equipe é complementada } \\
\text { por: Engenheiros Jr., Administradores e pessoas com } 2^{\circ} \text { Grau. Há atualmente uma maior capacitação das } \\
\text { pessoas dessa função quando a comparamos com o quadro de } 10 \text { anos atrás. }\end{array}$ \\
\hline Inepar & 4 & $\begin{array}{l}\text { As funções de PCP são executadas por Técnicos de nível médio, com comprovada experiência em processos } \\
\text { e produtos manufaturados sob encomenda, liderados por Engenheiros igualmente qualificados, inclusive } \\
\text { com pós-graduação em Engenharia de Produção. A capacitação atualmente exigida é maior que há dez anos, } \\
\text { proporcionada tanto por intensivos treinamentos como também pela capacidade individual de adaptação às } \\
\text { mudanças provocadas pelos processos de reengenharia. }\end{array}$ \\
\hline Itautec & 4 & $\begin{array}{l}\text { Trabalham no PCP Engenheiros e Técnicos de nível superior. Tem sido observada uma evolução na capa- } \\
\text { citação, não somente na formação profissional, como na melhor compreensão das operações da empresa } \\
\text { como um todo. }\end{array}$ \\
\hline Klin & 5 & $\begin{array}{l}\text { A capacitação das pessoas que trabalham no PCP é alta. Temos os melhores profissionais da região (in- } \\
\text { clusive, sendo um deles professor com mestrado na UNICAMP). Temos também, incentivado o estágio de } \\
\text { estudantes na função de processamento de dados para o desenvolvimento de trabalhos excepcionais. Em } \\
\text { relação aos últimos } 10 \text { anos essa capacitação aumentou. Isso é decorrente das necessidades colocadas pelo } \\
\text { próprio mercado. }\end{array}$ \\
\hline Villares & 5 & $\begin{array}{l}\text { Trabalham no PCP atualmente: Supervisor (engenheiro mecânico), Programadores (técnico mecânico, ad- } \\
\text { ministrador de empresas, matemático). } \\
\text { Em relação aos últimos } 10 \text { anos, essa capacitação aumentou por causa da necessidade de dominar a linha } \\
\text { de produtos e roteiros de fabricação (cuja complexidade está aumentando) e da necessidade de dominar } \\
\text { suficientemente o sistema de PCP e seus recursos. }\end{array}$ \\
\hline
\end{tabular}


Tabela 6. Prioridade do PCP e Investimentos em softwares para o PCP.

\begin{tabular}{|c|c|c|}
\hline Empresa & AGP & (Prioridade do PCP $) \times($ Investimentos em softwares para o PCP $)$ \\
\hline Abril & 5 & $\begin{array}{l}\text { Tem havido um crescente aumento na utilização de conceitos ao longo do tempo e esta tendência deve per- } \\
\text { manecer. Os atuais sistemas foram desenvolvidos internamente, pois, no momento do seu desenvolvimento, } \\
\text { não foram encontradas alternativas que pudessem ser adquiridas no mercado. A elaboração destas novas fer- } \\
\text { ramentas conta com uma equipe de especialistas, altamente qualificados, dedicados a este desenvolvimento } \\
\text { e apoiados por consultorias externas que têm procurado aproximar os conceitos teóricos de uma solução } \\
\text { prática viável. }\end{array}$ \\
\hline Alcoa & 1 & $\begin{array}{l}\text { Os conceitos utilizados seguem a linha do Sistema Toyota de Produção que está baseado na produção para } \\
\text { reposição de um estoque controlado que possui mínimos e máximos. A tendência é usar sistemas visuais e } \\
\text { auto gerenciáveis cada vez mais simples dentro dessa mesma linha. Não utilizamos nenhum tipo de software } \\
\text { para essa função. }\end{array}$ \\
\hline Baldan & 4 & \\
\hline Deca & 4 & \\
\hline Embraer & 4 & $\begin{array}{l}\text { A empresa baseia a operação de PCP em softwares diversos, tanto de mercado quanto desenvolvido interna- } \\
\text { mente. A utilização crescente desses softwares, de modo integrado, é que tem propiciado o suporte necessá- } \\
\text { rio à função PCP em vista do grande desenvolvimento da empresa nos últimos anos. Porém, para alavancar } \\
\text { esse contínuo crescimento, faz-se necessária a utilização cada vez maior de novos aplicativos, integrados } \\
\text { aos já existentes. Neste sentido, a empresa tem previsão de investimento tanto no desenvolvimento quanto } \\
\text { na compra de novos softwares. }\end{array}$ \\
\hline Faber & 4 & $\begin{array}{l}\text { Basicamente utilizamos: Planilhas Excel Estruturadas para cálculo da Previsão de Vendas e o SAP R/3 para } \\
\text { geração das Necessidades, acompanhamento da programação de produção e Suprimentos e Gestão dos } \\
\text { Estoques. Anteriormente, tínhamos software desenvolvido internamente (sob medida para as necessidades } \\
\text { da empresa). }\end{array}$ \\
\hline Inepar & 4 & $\begin{array}{l}\text { Há cerca de } 10 \text { anos, já tinham sido introduzidos na Empresa, os conceitos de MRP, por meio de software } \\
\text { desenvolvido internamente, e, na época, operando em ambiente "mainframe". Atualmente o principal siste- } \\
\text { ma utilizado pela empresa para aplicação no PCP está baseado em um software padrão, adquirido no merca- } \\
\text { do e fornecido pela "BAAN". O "BAAN" foi implantado na área fabril, em abril de 1999, com as missões } \\
\text { de aumento de produtividade e contribuição na questão do "bug do milênio". Superada a questão do "bug", } \\
\text { a constatação é que os softwares complexos e abrangentes desta natureza têm muita dificuldade (e custam } \\
\text { muito caro) no atendimento das especificidades de cada tipo de produção, em particular das manufaturas sob } \\
\text { encomenda não repetitivas, como as que a empresa opera. Assim, os resultados com produtividades ainda } \\
\text { não foram plenamente satisfeitos, dependendo de investimentos adicionais em customizações e adequações } \\
\text { do software. }\end{array}$ \\
\hline Itautec & 4 & $\begin{array}{l}\text { Utiliza vários softwares desenvolvidos sob medida por terceiros ou internamente. Sempre serão necessários } \\
\text { investimentos na informatização da função, o que estamos vivenciando neste momento. }\end{array}$ \\
\hline Klin & 5 & $\begin{array}{l}\text { Temos um produto Datasul, no qual adaptamos algumas necessidades conforme a realidade da empresa. } \\
\text { Não dispomos de tudo que desejamos para melhor adequação do PCP. Estamos buscando novos softwares } \\
\text { (prospectando e avaliando). }\end{array}$ \\
\hline Villares & 5 & $\begin{array}{l}\text { Utiliza software comercial desenvolvido sob medida por empresa externa, complementado por "queries" } \\
\text { (ou diversas sistematizações das informações) que o banco de dados permite obter. }\end{array}$ \\
\hline
\end{tabular}

Tabela 7. Abordagens de processos de tomada de decisão usadas no PCP.

\begin{tabular}{|c|c|c|c|c|c|c|c|c|c|c|}
\hline & Abril & Alcoa & Baldan & Deca & Embr & Faber & Inep & Itaut & Klin & Vill \\
\hline AGP do PCP & 5 & 1 & 4 & 4 & 4 & 4 & 4 & 4 & 5 & 5 \\
\hline $\begin{array}{l}\text { Exclusivamente na experiência } \\
\text { do decisor }\end{array}$ & 2 & & 3 & 5 & 6 & & 5 & 4 & 1 & \\
\hline $\begin{array}{l}\text { Na experiência do decisor apoia- } \\
\text { da em conceitos teóricos }\end{array}$ & 3 & & 1 & 2 & 4 & 2 & 2 & 3 & 2 & \\
\hline $\begin{array}{l}\text { Em regras de decisão simples } \\
\text { aceitas internamente }\end{array}$ & & 1 & 2 & 4 & 2 & 3 & 4 & 2 & 5 & \\
\hline Em modelos matemáticos & & & 6 & & 3 & & 6 & 5 & 6 & \\
\hline $\begin{array}{l}\text { Em sistemas informatizados } \\
\text { comerciais }\end{array}$ & & & 5 & 3 & 5 & 1 & 3 & 6 & 4 & 1 \\
\hline $\begin{array}{l}\text { Em sistemas informatizados } \\
\text { desenvolvidos internamente }\end{array}$ & 1 & & 4 & 1 & 1 & & 1 & 1 & 3 & \\
\hline
\end{tabular}


Tabela 8. Validação do modelo para determinação do foco do PCP.

\begin{tabular}{|c|c|c|c|c|c|c|}
\hline Empresa & $\begin{array}{c}\text { Produz } \\
\text { preponderantemente }\end{array}$ & $\begin{array}{c}\text { Variedade } \\
\text { de produtos } \\
\text { finais } \\
\end{array}$ & $\begin{array}{c}\text { Importa } \\
\text { insumos } \\
\text { relevantes }\end{array}$ & $\begin{array}{c}\text { Exporta de } \\
\text { forma signifi- } \\
\text { cativa }\end{array}$ & $\begin{array}{l}\text { Foco sugerido } \\
\text { pelo modelo }\end{array}$ & $\begin{array}{l}\text { Foco na } \\
\text { empresa }\end{array}$ \\
\hline Abril & Encomenda & Alta & Não & Não & Program. & Ambos \\
\hline Alcoa & Estoque & Baixa & Não & Sim & Planej. & Planej. \\
\hline Baldan & Encomenda & Alta & Não & Sim & Ambos & Planej. \\
\hline Deca & Estoque & Alta & Não & Não & Ambos & Ambos \\
\hline Embraer & Encomenda & Baixa & Sim & Sim & Ambos & Ambos \\
\hline Faber & Estoque & Alta & Não & Sim & Ambos & Ambos \\
\hline Inepar & Encomenda & Alta & Não & Sim & Ambos & Ambos \\
\hline Itautec & Estoque & Alta & Sim & Sim & Ambos & Ambos \\
\hline Klin & Encomenda & Alta & Não & Sim & Ambos & Ambos \\
\hline Villares & Encomenda & Alta & Não & Não & Program. & Program. \\
\hline
\end{tabular}

suas necessidades. Uma função é prioritária quanto mais o sucesso do negócio depende de seu desempenho. Uma função possui mais necessidades de recursos quanto mais complexos forem os seus processos ou os processos que ela deve controlar. Os mecanismos de controle devem ser mais complexos quanto mais complexos forem os processos a serem controlados.

Analisamos o PCP em 10 importantes empresas industriais brasileiras de ramos diferentes e em geral líderes no seu ramo de atividades. Vale ressaltar que o sucesso de uma empresa depende, entre outros fatores, do acerto dos executivos do grau de prioridade que atribuem às funções e do nível de necessidades de recursos que eles avaliam que cada função necessita para seu bom desempenho.

Da análise dos 10 casos observamos que os fatores principais que influenciam no grau de prioridade que deve ser atribuída são: nível competição do mercado em que atua; forma de atender à demanda (produção para estoque ou sob encomenda); complexidade da estrutura de produtos; complexidade das restrições tecnológicas ou organizacionais e a variedade de produtos finais.

Foi constatada total aderência entre o grau de prioridade atribuído ao PCP e o volume de recursos humanos e computacionais alocados à função: quanto maior o grau de prioridade, maior o volume alocado de recursos.

Outras conclusões:

i) quanto maior o grau de prioridade dado ao PCP, mais as decisões são baseadas em softwares;

ii) tem efeito sobre a escolha do foco do PCP (planejamento; programação; ambos): tipo de produção (para estoque ou sob encomenda), variedade de produtos finais, se importa de forma significativa e se exporta de forma significativa; iii) as combinações utilizadas de abordagens de processos de tomada de decisão empregadas no PCP são diversificadas; e

iv) as abordagens de processos de decisão empregadas seguem a seguinte ordem (da mais para a menos usada):

$1^{\circ}$. lugar) baseada em sistemas informatizados desenvolvidos internamente (57 pontos);

$2^{\circ}$. lugar) baseada na experiência do decisor apoiada em conceitos teóricos (45 pontos);

$3^{\circ}$. lugar) baseada em regras de decisão simples aceitas internamente (40 pontos);

$4^{\circ}$. lugar) baseada em sistemas informatizados comerciais (36 pontos);

$5^{\circ}$. lugar) baseada exclusivamente na experiência do decisor (28 pontos); e

$6^{\circ}$. lugar) baseada em modelos matemáticos (9 pontos).

Os depoimentos das empresas são bastante interessantes sob o ponto de vista prático e também teórico. Eles podem fornecer suporte ao desenvolvimento de modelos ou teorias que podem vir a influenciar a prática das empresas. A criação de dois modelos conceituais com tal finalidade é a tônica deste artigo.

\section{Agradecimentos}

Agradecemos às 10 empresas dos estudos de casos, a seus profissionais que responderam aos questionários e aos referees deste artigo a valiosa contribuição na melhoria da qualidade do texto. 


\section{Apêndice 1:}

\section{Questionário Sobre o PCP}

1) Faça um muito breve histórico da sua empresa, produtos e serviços.

2) Caracterize brevemente sua empresa marcando com um $(\mathrm{X})$ as respostas mais apropriadas às questões a seguir:

2a.Seu mercado é:

( ) Muito competitivo

( ) Pouco competitivo

2b.Produz principalmente:

( ) Sob encomenda

( ) Para estoque

2c.Seus produtos têm estrutura:

( ) Complexa

( ) Simples

2d.O processo produtivo tem restrições tecnológicas que o caracterizam como:

( ) Complexo

( ) Simples

3) Qual o grau de prioridade do PCP na sua empresa, atualmente, segundo a visão do responsável? Qual a posição dessa função no organograma de sua empresa?

4) Em relação aos últimos 10 anos esse grau de prioridade diminuiu, permaneceu estável ou aumentou? Justifique a sua opinião.

5) Qual a tendência ou perspectiva desse grau de prioridade no futuro? Justifique a sua opinião e comente também a perspectiva de investimentos futuros em hardware, software, pessoas e treinamento.

6) Qual a capacitação das pessoas que trabalham nessa função da sua empresa atualmente?

7) Em relação aos últimos 10 anos essa capacitação diminuiu, permaneceu estável ou aumentou? Justifique a sua opinião.

8) A globalização deixou o exercício dessa função mais complexo? Justifique a sua opinião.

9) Qual é a função responsável pela integração das atividades de toda a cadeia de suprimento na qual sua empresa está inserida?
10) O foco decisório da função PCP está:

( ) no planejamento

( ) na programação

( ) em ambos

11) As principais decisões de PCP são tomadas com base (responda priorizando as alternativas utilizadas - 1 , $2,3, \ldots)$ :

( ) Exclusivamente na experiência do decisor

( ) $\mathrm{Na}$ experiência do decisor apoiada em conceitos teóricos

( ) Em regras de decisão simples aceitas internamente

( ) Em modelos matemáticos

( ) Em sistemas informatizados comerciais

( ) Em sistemas informatizados desenvolvidos internamente

12) Faça uma avaliação dos conceitos atualmente utilizados e uma relação com aqueles utilizados no passado. Há uma tendência futura de se utilizar conceitos e modelos de decisão mais elaborados e mais próximos da teoria?

13) Sua empresa tem utilizado softwares no desempenho dessa função? Caso a resposta seja positiva comente se são softwares de mercado, desenvolvidos sob medida por empresa externa, desenvolvidos internamente ou uma mistura. Ainda nesse caso, faça uma avaliação dos resultados obtidos com a utilização desses softwares e perspectivas de novos investimentos em informatização da função.

\section{Apêndice 2}

\section{Resumo dos Depoimentos}

\section{ABRIL Editora}

"A empresa vê a função de PCP como muito importante para viabilizar, sincronizar e orquestrar todo o fluxo operacional de maneira a atender aos requisitos dos editores e leitores. As suas atividades estão diretamente ligadas a uma diretoria de programação, o que dá a exata dimensão de seu grau de prioridade.

$\mathrm{O}$ reconhecimento da prioridade da função PCP foi crescente no tempo, pois, anteriormente, somente a gráfica dispunha de uma função de PCP centralizada, enquanto a distribuição e armazenagem trabalhavam de forma isolada, com a função de programação diretamente ligada à operação. Durante a última mudança estrutural, foi criada uma diretoria de Atendimento, Planejamento e Logística que centralizou a função de programação para todo o processo. Esta centralização resultou em um ga- 
nho substancial em lead time e um melhor aproveitamento de recursos e de custos.

Com as pressões por lead times e custos reduzidos, percebemos que a função tende a ganhar cada vez mais importância. O crescente volume de operações também contribui para fortalecer a visão de que a função de PCP deverá ser cada vez mais valorizada pela empresa. Obviamente serão necessárias ferramentas que facilitem, melhorem e tornem mais rápidas as simulações necessárias.

Estamos prevendo investimentos pesados no desenvolvimento interno de sistemas que suportem este planejamento e programação integrados. A mesma integração e centralização de funções ajudou a fornecer uma visão global melhor, mas os atuais sistemas não permitem ou não facilitam que se tire proveito completo desta situação. Mesmo que alguns dos sistemas atuais, que evoluíram de antigos MRP II, utilizem conceitos modernos de programação, como o uso de simuladores, eles ainda focam apenas parte do problema de programação, ou seja, fornecem boas alternativas apenas para uma parcela da cadeia de produção, não assegurando que o todo será razoável. Daí a importância de se criarem novas ferramentas de trabalho ágeis modernas e integradas".

\section{$A L C O A$}

"Atualmente a função PCP foi incorporada ao setor de expedição tendo como principal atividade fazer a interface entre a fábrica e os clientes. A função está subordinada diretamente ao Superintendente do Lingotamento, que reporta ao Gerente de Redução, que, por sua vez, se reporta ao Gerente de Operações. A importância do PCP diminuiu consideravelmente nos últimos três anos dentro da Alcoa por causa da implantação de um sistema de negócios - o qual chamamos ABS (derivado do Sistema Toyota de Produção). O ABS trouxe um sistema de programação de produção totalmente visual e auto gerenciável que fez com que a função de PCP tradicional perdesse o seu sentido. Foi criada então uma nova função com outras responsabilidades, que continuamos a chamar de PCP.

A tendência é que esta função tenha cada vez menos prioridade com relação ao modelo tradicional. Ela continuará a existir sim mas, com uma nova descrição de cargo voltada ao atendimento de clientes. Não há nenhuma perspectiva de investimento nessa função nem no que se refere a software nem a pessoas".

\section{BALDAN}

"O grau de prioridade do PCP nesta gestão profissional da Baldan é elevada. A Diretoria entende que o PCP é o departamento responsável por coordenar o processo de negociação dos múltiplos planos departamentais, às vezes conflitantes entre si (por exemplo, Vendas e Produção), manter a coerência dos planos e implementar as estratégias da empresa por meio da elaboração dos planos operacionais (Plano Agregado e Plano Mestre de Produção).

O grau de prioridade do PCP atualmente é muito maior do que há 10 anos. No período passado a atividade do PCP estava restrita a colocar prazos nas ordens de venda, após consultar a produção, e emitir as ordens de produção. Gerente de Produção e Suprimentos decidiam informalmente o que comprar, quanto comprar e quando comprar, baseados em informações históricas e "feeling". Kanban estava ligado à Produção, e no caso de componentes comprados, direcionavam-no diretamente para Suprimentos.

A perspectiva é aumentar o grau de prioridade. Entende a diretoria que nessas fases de mudanças rápidas e freqüentes, de grande magnitude, a função de integração e coordenação dos planos operacionais dos múltiplos departamentos, baseada no plano agregado de produção, assume um valor crescente.

Caberá ao PCP não só desempenhar as funções tradicionais, como elaboração do plano agregado de produção, planejamento da capacidade, administração de matérias, controle de produção entre outros. Deverá este departamento ser membro efetivo do grupo de Engenharia Simultânea para melhoria de produtos atuais e desenvolvimento de novos produtos, coordenar processos de desverticalização, terceirização e subcontratação interna, desenvolver relatórios gerenciais da manufatura".

\section{DECA}

"O negócio metais sanitários faturou 255 milhões de reais em 2000, produzindo mais de 850 mil produtos / mês em mix variado (4000 produtos ativos e 2000 subconjuntos para reposição), operando em parque de 450 equipamentos. Este mercado vem apresentando nos últimos anos uma característica de forte concentração de entrada de pedidos nos últimos dias do mês, o que torna o planejamento da produção, bem como a expedição de produtos bastante complexa.

Consideramos que boa parte das funções básicas de um empreendimento está, de uma forma ou de outra, relacionada aos seus fatores de sucesso. No caso do Planejamento e Controle da Produção, há forte correlação com os seguintes fatores:

- Custo (de produto e de operação - estoques; constantes reduções de inventários que podem representar milhares de reais de economia financeira por mês);

- Agilidade / Garantia de Prazo de Entrega;

- Flexibilidade no lançamento de novos produtos;

- No prazo de entrega, entendemos que o mercado diferencia cada vez com maior intensidade as empresas capazes de agilizar a entrega de seus produtos, e, se 
possível, permitir perfeita rastreabilidade de posição de pedidos, garantindo datas confiáveis de entrega; e

- Na agilidade de lançamento de novos produtos, o que exige plena organização dos recursos - novos ou existentes - que deverão ser utilizados ou compartilhados para a implantação de novos produtos.

Exercitamos atualmente na DECA mais Planejamento de Produção do que Programação de Produção, uma vez que, sobre um Plano Mestre e políticas de estoque de semi-elaborados bem definidas, damos autonomia de gestão de produção para as diversas células de manufatura nas quais está dividida a fábrica, e que trabalham sob o conceito de "kanban eletrônico" (não são geradas ordens de produção).

Este processo de trabalho alimenta o depósíto de componentes acabados que supre nossa montadora, esta sim programada diariamente.

No caso de insumos, trabalhamos tanto no Planejamento quanto na programação, definindo volumes / prazos de entrega para todos os itens consumidos na fábrica. Vale ressaltar que os processos de aquisição estão centralizados na corporação.

Nunca o tema "aumento de produtividade" esteve tão em destaque, principalmente, após a abertura do mercado brasileiro e, principalmente, a estabilização da moeda e a conseqüente queda da inflação. Todas as oportunidades de redução de custos e racionalização da operação são exploradas, pois cada uma destas ações pode gerar melhores resultados para a companhia - e fica fácil comprovar estes ganhos - coisa que não ocorria em passado recente.

Desta forma, atualmente, a busca da excelência na operação, aliada à disponibilidade de informações de operações similares, senão de concorrentes, tem alçado o Planejamento Industrial, em seu contexto mais amplo, à posição de muito maior relevância dentro da estratégia do negócio.

Com certeza, a busca "paranóica" por ganhos de produtividade e aumento de competitividade deve ser a tônica dos próximos 10 anos. Desta forma percebemos que a tendência é de ampliarmos o grau de prioridade das funções que alavancam o desempenho das companhias.

Temos a percepção na DECA de que os processos administrativos de apoio à operação, dentre eles o de Planejamento da Produção, devem caminhar na mesma velocidade do piso de fábrica. Lá são feitos pesados investimentos visando racionalizar/dar regularidade aos processos de produção, deixando-os sempre em face com o que há de mais moderno em termos de tecnologia e conceito.

Da mesma forma, iniciamos o processo de identificação das nossas principais lacunas em termos administrativos, visando à proposição de projetos de adequação (quer digam respeito a Sistemas de informação ou racionalizações de procedimentos) e, neste contexto, há perspectiva de investimento neste setor".

\section{EMBRAER}

"Planejamento se faz muito presente e intensivo nas áreas de Fabricação, Compras e Peças de Reposição, com uma visão de curto e médio prazo, ficando a de longo prazo para a área estratégica da Empresa.

A programação está alicerçada em conceito de MRP e ponto de pedido. Para peças de reposição temos um planejamento flexível por planta, ancorado em modelos de previsão, consolidando as necessidades para compras e fabricação e distribuição focando as necessidades dos Clientes.

Os profissionais que administram estas atividades possuem cargos de Gerentes e estão ligados diretamente às Diretorias de Produção, Suprimentos e Suporte ao Cliente, as quais respondem a Vice-Presidentes.

O grau de prioridade é cada vez maior, pois a complexidade das nossas operações tem crescido substancialmente.

Os investimentos tanto em treinamentos conceituais, benchmarks, ferramentas e desenvolvimentos são sempre incentivados e requeridos.

Existe uma indiscutível tendência de crescimento. Estamos crescendo, descentralizando e globalizando nossa cadeia e, neste contexto, torna-se vital aumentar o grau de prioridade do PCP. Investindo continuamente, buscando os melhores processos e ancorando-os nas melhores soluções, apoiadas em pessoas competentes e treinadas estamos dando suporte adequado a este ambiente".

\section{FABER}

"Atividade bastante valorizada com enfoque na Integração entre as diversas áreas da empresa (Bastante Verticalizada), Gestão dos Estoques e Nível de Atendimento aos requerimentos dos Clientes. A atividade tem se tornado prioritária em função da diversidade crescente dos Produtos da Empresa ao longo do tempo, do valor envolvido em estoques e da necessidade de integração dos processos logísticos no sentido de minimizar os custos e melhorar o Nível de Serviço.

Como dito anteriormente, em função da diversidade crescente dos Produtos e da contínua necessidade de melhorarmos a Gestão dos Estoques e o Nível de Serviço ao Cliente como vantagem competitiva, a tendência é de aumento do grau de prioridade dessa atividade".

\section{INEPAR}

"A INEPAR é uma indústria do tipo intermitente com fabricação sob encomendas de produtos diferentes. Esta característica, por si só, evidencia a prioridade e os desafios que são oferecidos à função PCP, quando comparados com as indústrias do tipo contínuo, ou mesmo com 
as indústrias do tipo intermitente, mas com fabricação repetitiva.

A posição da função PCP no organograma é de ligação direta com a Diretoria de Fabricação.

É clara a influência que a globalização das economias tem exercido nas atividades industriais, que são globais por natureza.

Mudanças dramáticas nas práticas das manufaturas estão sendo impostas pelos padrões de competitividade de classe mundial, implicando no aumento de utilização de ativos, maior qualidade, menores custos, maior produtividade, menores tempos de produção, e rápida aprendizagem com os competidores.

Assim, a função PCP tem sido cada vez mais exigida para contribuir com o aumento da competitividade industrial.

Tendo em vista que o processo de globalização é irreversível, pelo menos a curto e médio prazos, a perspectiva é de importância crescente da contribuição do PCP na competitividade manufatureira.

A perspectiva é de investimentos contínuos na customização ou mesmo substituição dos atuais e complexos softwares comerciais, assim como é inexorável a necessidade de atualização de hardwares. A decorrência natural é o treinamento e desenvolvimento dos respectivos funcionários.

Desta forma, a questão de investimentos em informática desloca-se do clássico "plano de investimento específico" para o "plano de despesas correntes da organização".

\section{ITAUTEC-PHILCO}

"Nesta divisão, a função PCP está ligada às áreas de Manufatura. Podemos classificar o grau de prioridade da função sob dois aspectos, ou seja, na visão interna da função e na interface com os clientes:

- Interface com clientes - em qualquer das Manufaturas da Divisão, os clientes são empresas transformadoras, portanto, a conexão do nosso $\mathrm{PCP}$, não está vinculado diretamente a um Mercado Consumidor Final. Esse fato faz com que estejamos vinculados no Sistema de Planejamento de cada cliente, operando como um parceiro, em condições que abrangem desde qualidade assegurada, JIT delivery, etc., acrescido do fato desses clientes estarem localizados tanto no exterior como em várias regiões brasileiras.

- Visão interna da função - a necessidade de competir em nível mundial em custos, qualidade, atendimento, etc., faz do processo de planejamento um elemento diferencial importante.

Entendo que a função PCP, sempre teve um papel destacado nas organizações, o que observo nos últimos anos, como de fato tem ocorrido em todas as funções, é uma transformação como consequiência da própria mudança verificada. $\mathrm{O}$ que acredito tenha sido a maior transformação pela descentralização de algumas funções, como controle de produção, seqüenciação de ordens, etc., que tem sido ou exercida por técnicas específicas (como Kanban, etc.) ou diretamente atribuídas às áreas executoras. Por outro lado a função passa a se dedicar aos problemas de Logística como um todo, que adquiriu uma importância fundamental no resultado das organizações, no dimensionamento dos recursos e no processo analítico, o qual pessoalmente considero como o centro da inteligência da função.

Acredito que a função deve avançar, nos próximos anos, no caminho da simplificação, automação e/ou delegação de funções repetitivas, e cada vez mais ganhar espaço nos processos estratégicos e analíticos que possibilitem gerar um diferencial de competitividade para as organizações. Nessa linha, modelo de simulação de fácil e rápida aplicação deve se popularizar mais na função".

\section{$K L I N$}

"A posição do PCP na empresa é de grande relevância e fundamental para o melhor desempenho na definição/ investimento e planejamento de uma forma geral.

É dado destaque no organograma como função de suma importância, para maximização de recursos e minimização de despesas (planejamento de materiais e recursos para fabricação/mod/eqpto/outros).

O grau de prioridade do PCP nos últimos 10 anos aumentou. Haja vista a necessidade premente do mercado na redução de custo de processo de fabricação. Buscamos permanentemente a melhoria sistêmica de geração de informação para a produção, melhorando a definição de família tecnológica de produto por meio de similaridade de seqüência operacional, maximização de equipamento com montagem de células de fabricação, dando maior flexibilidade ao processo e ganhos no fluxo.

A tendência é que a prioridade continue a aumentar. Já estamos prospectando novos recursos de software, pois dispomos do melhor hardware no momento (top de linha).

Temos treinamento constante de profissionais, sendo realizado por monitores internos com recursos próprios".

\section{VILLARES}

"O grau de prioridade do PCP é muito grande. O PCP está subordinado ao Gerente de Produção.

Em relação aos últimos 10 anos essa importância aumentou por causa do aumento da produção (acarretando o aumento da ocupação da fábrica, diminuindo assim a margem de erro possível).

A tendência é a de manter ou aumentar sua prioridade por causa da crescente exigência de precisão de entregas no mercado internacional.

Os investimentos na função visarão a manter a atua- 
lização do hardware e do software, e treinar as pessoas para obter o máximo de recursos (particularmente das in- formações que o banco de dados possibilita obter, e das alternativas de simulação disponíveis)".

Referências Bibliográficas

ANDIJANI, A.; SELIM, S. The practice of production control techniques in the manufacturing sectors in the eastern province of Saudi Arabia. International Journal of Production Economics, v. 43, n. 2-3, p. 251-258, June 1996.

BRYMAN, A. Research methods and organization studies. London: Uniwin Hyman, 1989.

BUFFA, E. S.; MILLER, J. G. Productioin-Inventory Systems Planning and Control. Richard D. Irwin, 1979.

CRESWELL, J. W. Research design - qualitative \& quantitative approaches. London: Sage, 1994.

FILIPPINI, R. Operations management research: some reflections on evolution, models and empirical studies in OM. International Journal of Operations and Production Management, v. 17, n. 7, p. 655-670, 1997.

GUIDE, V. D. R. Production planning and control for remanufacturing: industry practice and research needs. Journal of Operations Management, v. 18, n. 4, p. 467-483, June 2000.

GUIDE, V. D. R.; JAYARAMAN, V.: Production acquisition management: current industry practice and a proposal framework. International Journal of Production Research, v. 38, n. 16, p. 3379-3800, November, 2000.

HARSALL, D. N.; MUHLEMANN, A. P.; PRICE, D. H. R. A review of production planning and scheduling in smaller manufacturing companies in the UK. Production Planning \& Control, v. 5, n. 5, p. 485-493, SeptemberOctober 1994.

MACCARTHY, B. L.; FERNANDES, F. C. F. A multi-dimensional classification of production systems for the design and selection of production planning and control systems. Production Planning \& Control, v. 11, n. 5, p. 481-496, 2000.

MATSUURA, H.; KUROSO, S.; LEHTIMAKI, A. Concepts, practices and expectations of MRP, JIT and OPT in Finland and Japan. International Journal of Production Economics, v. 41, n. 1-3, p. 267-272, October 1995

MESQUITA, M. A. Análise de modelos e práticas de planejamento e programação da produção: estudo de caso na indústria farmacêutica. Tese de Doutorado, EP-USP, 2001.

MORRIS, J. S.; KIM, W.-J. Manufacturing planning and control in Korea. Production and Inventory Management Journal, p. 39-43, First Quarter 1988.

PACHECO, R. F.; SANTORO, M. C. A adoção de modelos de scheduling no Brasil: deficiências do processo de escolha. Gestão \& Produção, v. 8, n. 2, p. 128-138, Agosto 2001.

PERSSON, G. Towards a production management theory: I. Theoretical foundation in Production Management. In Wild, R. (editor): Management and Production Readings, p. 15-23. England: Penguin Books Ltd., 1981a.

PERSSON, G. Towards a production management theory: II. A tentative conceptual framework for the study of Production Management Systems. In Wild, R. (editor): Management and Production Readings, p. 24-37. England: Penguin Books Ltd., 1981b.

RUSSO, R. D. B. Aplicabilidade dos sistemas de Planejamento e Controle da Produção na indústria pesada de bens de capital sob encomenda de produtos não repetitivos. Dissertação de Mestrado, EESC/USP, 1997.

SANDERS, N. R.; MANRODT, K. B. Forecasting practices in US corporations: survey results. Interfaces, v. 24, n. 2, p. 92-100, March-April 1994.

WILD, R. The techniques of production management. London: Holt, Rinehart and Whinston, 1971.

WILD, R. Mass production management. London: Wiley, 1972.

WILD, R. Production and operations management (5th edition). London: Cassell Educational, 1995. 


\section{ASSESSMENT OF THE PRIORITY AND FOCUS OF PRODUCTION PLANNING AND CONTROL (PPC): MODELS AND CASE STUDIES}

Abstract

Two models are proposed in this paper: the first suggests the degree of priority a company should give to Production Planning and Control (PPC), while the second suggests the decision-making focus PPC should concentrate on, i.e., planning, scheduling, or both planning and scheduling. The two models are validated through case studies of ten major Brazilian manufacturers.

Keywords: production planning, production control, production scheduling, degree of priority, industrial practice. 